\title{
LOS AVATARES DE UN NOMBRE: SAAVEDRA Y CERVANTES
}

\author{
MARÍA ANTONIA GARCÉS \\ Cornell University
}

¿Cuáles son los avatares que subyacen en la elección de un nombre? ¿Qué posibles vicisitudes y constelaciones afectivas se entrelazan en el voto secreto, decisivo, que lleva a un hombre de casi cuarenta años a seleccionar un segundo apellido? ¿Cómo se yuxtapone la actividad artística del escritor que conjura, por virtud de la palabra, a la vida, con la recreación de la propia vida a partir de un nuevo nombre? Éstas son algunas de las preguntas que surgen al reflexionar acerca de la adopción del apellido Saavedra por parte del novelista Miguel de Cervantes ${ }^{1}$.

Pese a lo que se cree comúnmente, Saavedra no era el apellido de Cervantes, ni tampoco un patronímico que llevaran sus antepasados directos. El escritor asumió este apellido algunos años después de su retorno de Argel, donde estuvo cautivo cinco años, desde 1575 hasta 1580. Este apelativo adquiere una significación extraordinaria a la luz de la creación literaria cervantina, porque Saavedra es también el nombre otorgado por el autor a varios de sus personajes más sugerentes: el héroe de su drama $E l$ Trato de Argel, compuesto entre 1581 y 1583, después de su retorno de Berbería, lleva el nombre de Saavedra, y el protagonista de El gallardo español, comedia que dramatiza el ataque al presidio hispano de Orán, en 1563 , por una poderosa armada turcoberberisca, también se denomina Don Fernando de Saavedra. Finalmente, entre otros avatares que unen este nombre a una constelación afectiva en la vida y obra de Cervantes, Saavedra es el nombre del valeroso soldado cristiano que suscita la admiración del

\footnotetext{
${ }^{1}$ Este trabajo es una reelaboración de parte del capítulo 4, «An Erotics of Creation: La historia del cautivo» [Una erótica de la creación: La historia del cautivo], de mi libro Cervantes in Algiers: A Captive's Tale (Vanderbilt University Press, 2002).
}

Rlit, LXV, 130 (2003), 351-374 
cautivo Ruy Pérez de Viedma en La historia del cautivo, interpolada en El Quijote de 1605. Puesto que para la época en que aparece El Quijote, su autor ya llevaba más de quince años firmando «Miguel de Cervantes Saavedra», tanto en documentos oficiales como en su obra literaria, el nombre Saavedra puede leerse como la intrusión de la firma cervantina en La historia del cautivo, novela autobiográfica que nos interroga desde el doble registro de la historia y de la ficción. En estas páginas, me propongo explorar las particularidades que distinguen a la serie de personajes bautizados con el apellido Saavedra en los textos de Cervantes, análisis que también tendrá en cuenta la adopción de este nombre por parte del autor.

\section{EL NOMBRE PROPIO Y LA' MUERTE}

La alianza entre la vida y la obra de Cervantes y, especialmente, el oscilante límite entre la historia y la ficción en nuestro gran escritor, me llevan a acercarme a estos temas desde una perspectiva interdisciplinaria, enfocando el complejo tejido de vida y creación en Cervantes a partir de un diálogo entre los estudios biográficos, la crítica literaria, la filosofía y el psicoanálisis. El filósofo Jacques Derrida nos ofrece avenidas especialmente fecundas para aproximarnos a estos temas. En su libro Otobiographies (1984), dedicado al estudio del Ecce Homo de Nietzsche, Derrida pregunta qué es lo que un autor arriesga cuando pone su nombre en un trabajo escrito. Jugarse el nombre (con todo lo que éste conlleva), poner en escena firmas, crear una inmensa rúbrica biográfica con todo lo que uno ha escrito es, como afirma Derrida, «un hecho de vida y de muerte». El nombre, que debe distinguirse siempre de quien lo ostenta, apunta invariablemente a la muerte (Otobiographies, 7). Derrida regresa a los vínculos entre el nombre propio y la muerte en varios textos, específicamente en su emocionado adiós al ensayista y crítico literario Roland Barthes, donde el filósofo francés sugiere que el nombre propio solo y en sí mismo «dice muerte, todas las muertes en una. Dice muerte incluso cuando el que lo ostenta está aún viviendo [...]. La muerte se inscribe precisamente en el nombre» («The Deaths of Roland Barthes» 34 ). En su ameno y esclarecedor diálogo intertextual con Derrida, Geoffrey Bennington explica esta articulación entre el nombre propio y la muerte: «Mi propio nombre me sobrevive. Después de mi muerte, será posible nombrarme y hablar de mí. Como todo signo, incluyendo el «yo», el nombre propio incluye la necesaria posibilidad de funcionar en mi ausencia, de desprenderse de su portador». De esta suerte, «debemos llevar esta ausencia a un tipo de absoluto que llamamos muerte»: El nombre, la firma, es ya «el nombre de la persona muerta, la memoria anticipada de una partida» (148). Como veremos 
más adelante, estas reflexiones sobre el significado del nombre propio iluminan el sentido del apellido Saavedra en la vida y obra de Cervantes, así como sus vínculos con la muerte y la supervivencia, es decir, con la muerte vivida de antemano por el esclavo Miguel de Cervantes durante su cautiverio argelino.

El apellido Saavedra aparece en la frontera entre la «vida» y la «obra» de Cervantes, esa móvil y poderosa frontera que se halla entre los textos del autor alcalaíno, por un lado, y la vida del escritor identificado con el nombre de Miguel de Cervantes Saavedra, por el otro. Siguiendo a Derrida en The Ear of the Other [La oreja del Otro], quiero proponer que ese límite divisible atraviesa dos «cuerpos»: el cuerpo y el corpus (la obra) de Cervantes, de acuerdo con leyes que apenas comenzamos a vislumbrar. En ese tenue hilo divisorio entre el cuerpo y la obra surge el nombre Saavedra como testimonio de una experiencia limítrofe y como símbolo de la fundación de mundos nuevos que presagian el nacimiento de un nuevo yo. Examinar la vida y obra de Cervantes desde estas perspectivas presupone un reto enorme porque, como sabemos, Cervantes avanza camuflado detrás de máscaras, nombres y seudónimos con los que intenta disimular sus marcas en el texto. El hecho de que las creaciones cervantinas estén tan profundamente entrelazadas con la vida del autor me lleva a acercarme a estos temas de la misma manera, en un zigzag que se moverá de la vida a la creación, y viceversa, a través de la compleja trama de vida y ficción en Cervantes.

\section{VIDA Y CREACIÓN}

Como mencioné anteriormente, Saavedra no era el apellido de Cervantes, ni tampoco un nombre que llevaran sus antepasados cercanos. El autor adoptó este apellido algunos años después de su retorno de Argel, donde sufrió un largo y difícil cautiverio a manos de corsarios argelinos (15751580 $)^{2}$. Al llegar cautivo a Argel, Miguel de Cervantes tenía veintiocho años. Antes de participar como soldado de Felipe II en las guerras mediterráneas contra los turcos y en la batalla de Lepanto (1571), había escrito

\footnotetext{
${ }^{2}$ Para la historia de este cautiverio y sus efectos sobre la ficción cervantina, véase GARCÉs, Cervantes in Algiers: A Captive's Tale. Es posible que Cervantes ya haya usado el nombre Saavedra en Argel, en un memorial redactado por el Dr. Antonio de Sosa y dirigido al Papa Gregorio XIII y a Felipe II por varios cautivos en 1580 , entre cuyas firmas se encuentra la de Miguel de Cervantes Saavedra. El documento fue publicado por Cristóbal PÉREZ PASTOR en Documentos cervantinos hasta ahora inéditos, II: 37980, n. 1; fue incluido en la crónica de la Orden de la Merced de Fray Bernardo de Vargas, Cronica Sacri et militare Ordinis B. Mariae de Mercede, redemptionis captivorvm [...], Palermo, 1622, 107-109.
} 
una serie de poemas que fueron posteriormente publicados. A su regreso a España después de su liberación, en 1580 , se embarcó en una carrera multifacética como escritor que cubriría todos los géneros literarios, desde el drama hasta la poesía, incluyendo, por supuesto, la prosa narrativa. El hispanista Jean Canavaggio aduce que la experiencia argelina no solo le abrió horizontes nuevos a Cervantes: «Le ayudó, con el contacto de la adversidad, a revelarse a los demás tanto como a sí mismo. Por ese motivo, fue el crisol en que, tras Lepanto, se forjó su destino personal» ${ }^{3}$. Entre las fases cambiantes de este destino están los diferentes usos del apellido Saavedra, utilizado varias veces por Cervantes en su ficción, y finalmente asumido por el autor como un segundo apellido.

Un pariente lejano, Gonzalo Cervantes Saavedra, seguramente influyó sobre Cervantes en su elección de un segundo nombre. Poeta y escritor, Gonzalo tuvo que abandonar su Córdoba natal en 1568 después de un sangriento duelo, una historia similar a la del joven Cervantes, quien quizá escapó de Madrid por motivos similares en 1569 (Astrana Marín, I: 2325). Gonzalo se había embarcado en las galeras de don Juan de Austria y, por tanto, posiblemente peleó también en Lepanto. Miguel debió haberlo conocido personalmente, ya que incluyó el nombre de Gonzalo Cervantes Saavedra entre los poetas cordobeses elogiados en el "Canto de Calíope» de La Galatea (1585). Arruinado después de una vida soldadesca disipada, Gonzalo zarpó para las Indias en 1594, pero pereció en un naufragio cerca del puerto de La Habana (Astrana Marín, I: 26-27). Le hubiese servido de modelo o no este Gonzalo, lo cierto es que Cervantes revela su fascinación por el nombre Saavedra, como veremos a continuación.

El apellido Saavedra aparece por primera vez en El trato de Argel, drama compuesto por Cervantes después de su regreso de Berbería. Saavedra, el soldado cautivo que funciona como portavoz del autor, emerge en esta obra en medio de un gran número de personajes históricos y de ficción. Representando el modelo épico del cautivo cristiano que afirma su fe y patriotismo incluso frente a la muerte, el personaje Saavedra sugiere una imagen idealizada del yo creada por Cervantes durante el cautiverio con miras a afianzar su propia supervivencia psíquica. Como ha planteado Ciriaco Morón Arroyo, «Cervantes tuvo la experiencia más dura y más enriquecedora que puede tener el hombre: el cautiverio. Estar cautivo es vivir intensamente la experiencia de que no debes contar jamás con el próximo instante» (Nuevas meditaciones del Quijote, 139). El encuentro con la muerte marca radicalmente El trato de Argel, obra que inaugura la insistente repetición de testimonios literarios cervantinos sobre su experiencia argelina. Este drama no solo representa un testimonio personal y co-

\footnotetext{
${ }^{3}$ Rodríguez Marín plantea que Miguel de Cervantes pudo haber ido a la escuela primaria en Córdoba con Gonzalo Cervantes Saavedra («Los Cervantes cordobeses»).
} 
lectivo sobre las vicisitudes de la esclavitud en Argel sino que surge, simultáneamente, en Cervantes como un fruto del trauma del cautiverio. El trauma implica haber sido traspasado por la muerte, haberla vivido de alguna manera (Cervantes in Algiers, 174-77). Es Saavedra, un alter-ego de Cervantes, quien recita uno de los más hermosos versos de indudable sabor autobiográfico en esta obra dramática:

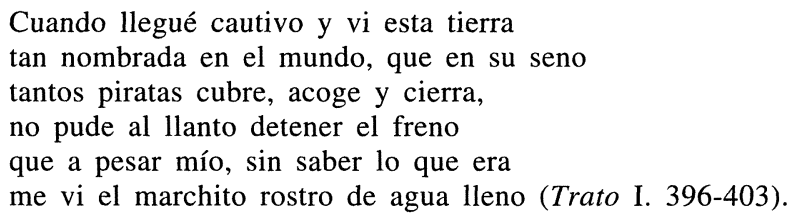

Cervantes le otorga de nuevo el nombre Saavedra al héroe de $E l$ gallardo español (c. 1597-1606), comedia que dramatiza el ataque turcoberberisco al presidio español de Orán, en 1563, por las tropas de Hasán Pachá, el hijo de Barbarroja. Vale recordar que unos meses después de su liberación, en mayo-junio de 1581, Cervantes viajó a Orán en una misión realizada para los servicios secretos de Felipe II. Allí se entrevistó con el Gobernador de Orán, Don Martín de Córdoba, a quien el ex-combatiente de Lepanto debió haberle contado su largo cautiverio en Argel, así como sus dos intentos de escapar hacia Orán, el primero en 1576, y el segundo en 1578 - éste constituye el tercer intento de fuga de Cervantes de su prisión argelina. En esta tentativa de evasión, planeada en 1578, Cervantes le envió una carta al gobernador de Orán, en la que le solicitaba ayuda para escapar del baño de bey (gobernador) de Argel, Hasán Pachá, junto con varios caballeros cristianos. El moro amigo que lleva la carta fue apresado a las puertas de Orán, devuelto a Argel a manos de Hasán Pachá y, finalmente, empalado. Por su parte, el cautivo Cervantes estuvo a punto de perder la vida en este episodio (Canavaggio, 98-99; Cazenave, «Cervantès à Oran», 215-42). Don Martín de Córdoba conocía bien el baño del bey de Argel, pues años atrás había sido prisionero de los argelinos ${ }^{4}$. A su vez, don Martín debe de haberle relatado a Cervantes la historia de la heroica resistencia española en el presidio de Orán durante el asedio turcoberbe-

${ }^{4}$ Capturado en la trágica derrota de Mostaganem (1558), en la que su padre, el conde de Alcaudete y gobernador de Orán, perdió la vida, Don Martín de Córdoba fue apresado junto con miles de soldados españoles. Poco después, intentó organizar una rebelión entre los esclavos cristianos de Argel. Fue delatado y miles de cautivos fueron ejecutados. Su rescate costó la enorme suma de 23.000 escudos de oro (Antonio de SoSA, Topografía e historia general de Argel, ed. Diego de Haedo, I: 96-97). Como han demostrado Georges Camamis, Emilio Sola y José María Parreño, y Garcés (Cervantes in Algiers), esta obra fue compuesta por Antonio de Sosa durante su cautiverio en Argel, entre 1577 y 1581 . Por tanto, cito la Topografía con el nombre de su verdadero autor, Sosa. 
risco de 1563, resistencia evocada por el futuro autor en su drama $E l g a$ llardo español, cuya acción tiene por telón de fondo la intrépida defensa de la ciudad contra los turcos. De hecho, don Martín de Córdoba había sido uno de los héroes de esta épica resistencia contra los ejércitos otomanos.

Más allá de la experiencia común del cautiverio vivida con veinte años de distancia aproximadamente, el soldado de Lepanto y el héroe del sitio de Orán parecen haber tenido otros puntos de contacto. El gobernador de Orán era un hombre de frontera, esa opresiva frontera entre la España cristiana y el mundo musulmán que, con la conquista del reino de Granada por los Reyes Católicos, en 1492, se desplazó hasta las costas africanas. La toma de Granada parece ser retrospectivamente el último episodio de una larga saga. Sin embargo, la Reconquista de la Península Ibérica se prosiguió en la reconquista del norte de África. El estrecho de Gibraltar no se contemplaba como una frontera natural sino como un lazo entre dos zonas que habían estado unidas durante mucho tiempo. Así, desde fines del siglo $\mathrm{XV}$, los españoles se dedicaron a la conquista de los pueblos costeros africanos. La visión de un mundo hispano-cristiano más allá de la península surge claramente en el testamento de la reina Isabel la Católica (1504), quien alienta a sus súbditos a continuar la lucha contra el Islam conquistando el norte de África ${ }^{5}$. Gracias a la financiación de aristócratas destacados, del clero y de las ciudades, que también aportaron la mayor parte de los recursos humanos, constituidos generalmente por voluntarios, los españoles lograron adueñarse de pueblos costeros en la costa del Magreb, adonde construyeron presidios: Melilla (1497), Marsa el-Kebir (1505), Peñón de Vélez (1508), Orán (1509), Mostaganen, Tlemcen, Peñón de Argel y Bujía (1510). Estas plazas se consideraban como bases para la conquista del interior. La frontera hispánica mediterránea se desplaza, por tanto, en el siglo XVI hasta el norte de África.

En la década de 1570, esta frontera político-religiosa estaba constituida por la misma cuenca mediterránea y, en particular, por los presidios españoles norteafricanos. El más importante de estos presidios era el de Orán, que se erguía como una isla olvidada en medio de los territorios enemigos del norte de África. Heridos de muerte en virtud del poco apoyo e interés mostrado por Carlos V y posteriormente por Felipe II, los presidios norteafricanos irán cayendo paulatinamente ante el empuje de los musulmanes. A mediados del siglo XVI, de las conquistas originales españolas solo quedaban Melilla, Marsa el-Kebir, Orán y Bujía. Entre estos bastiones del poder

\footnotetext{
${ }^{5}$ Véase Dousinague, La política internacional de Fernando el Católico, y Testamentaria de Isabel la Católica, ed. Antonio de la Torre y del Cerro, 445-75. El notable libro de M. J. Rodríguez SALAdo, Un imperio en transición: Carlos V, Felipe II y su mundo, 1551-1559 estudia minuciosamente estos temas.
} 
hispano-cristiano, Orán se había erigido en la nueva frontera en la cruzada española contra el islam. Una relación sobre un desafío entre moros y cristianos, publicada en Sevilla en 1554, efectivamente aclara que los caballeros cristianos tienen que pelear continuamente «en Orán porque es frontera» (citado por Redondo, 59).

En su Tesoro de la lengua castellana o española, Covarrubias define el término «frontera» como «la raya y término que parte dos reinos, por estar el uno frontero del otro». De la misma manera, el adjetivo «fronterizo» se usaba en el siglo XVI para calificar a los individuos que servían en las fronteras, especialmente a los soldados que guardaban estos territorios. La oposición y contigüidad evocadas por estas definiciones hallaban un eco en la vida de los presidios norteafricanos, donde los soldados españoles establecían relaciones con sus vecinos bereberes o moros y, a la vez, peleaban contra estos enemigos. Si por un lado, los gobernadores de Orán habían cultivado cuidadosamente la amistad de las tribus locales de Tlemcen, creando una red de alianzas que constituyeran una frontera o estado tapón a su alrededor, por el otro, por medio de razzias y de expediciones de castigo constante al otro lado de estos límites, se habían convertido en una fuerza importante en la política del Magreb. Como su padre y hermanos, don Martín de Córdoba fue un «soldado fronterizo.» Esto lo asocia con el protagonista de El gallardo español de Cervantes.

El héroe de la comedia El gallardo español, don Fernando de Saavedra, es un hombre de frontera que fluctúa entre el enclave español de Orán y el aduar en el que habita la bella mora Arlaxa. Como típico hombre de frontera, don Fernando responde al reto lanzado por un moro y cruza al campo enemigo, donde fraterniza con el adversario e incluso se viste de moro. Sin embargo, durante el ataque turcoberberisco a Orán, el héroe se vuelve contra los moros y defiende heroicamente el presidio cristiano amenazado. Su ambigua situación es subrayada por la pregunta incisivamente repetida en Orán: «¿Que sea moro, don Fernando?», pregunta que se responde con una afirmación: «Así lo van pregonando / los niños por la ciudad» (Gallardo, vv. 1280-1283) ${ }^{6}$. La obra dramática de Cervantes recalca la inquietante realidad de estos hechos históricos. Desertar y cambiar de bando, «volviéndose moro», era muy común en los presidios norteafricanos, donde los soldados españoles sufrían terribles privaciones (García Arenal y de Bunes, 238-55). Unos datos históricos iluminan el doloroso panorama de estas guarniciones a mediados del siglo XVI. En 1556, el conde de Alcaudete informaba a la corona de que la falta de dinero y provisiones había provocado una deserción masiva entre sus hombres, añadiendo asimismo que la guarnición se estaba desintegrando: el Estado español debía

${ }^{6}$ Véanse CAZENAVE, «El gallardo español (1)» y «El gallardo español (2)»; Zimic y Gerli. CARRASCO URGOITI estudia El gallardo español como héroe fronterizo. 
entonces más de 130.000 ducados en salarios atrasados a los defensores de Orán ${ }^{7}$.

Basado en el histórico don Fernando de Cárcamo, quien defendió heroicamente la fortaleza de Marsa el-Kebir durante el sitio de Orán de 1563, Don Fernando de Saavedra también recuerda al valiente cautivo de los romances de «Río-verde» que concluyen la primera parte de las Guerras civiles de Granada de Ginés Pérez de Hita. El «Romance de Sayavedra» alude a la histórica figura de Juan de Sayavedra, capturado por los moros de Granada en 1448, durante una expedición cerca de Marbella (Romancero viejo, 75; Pérez de Hita, 308-11). Es significativo que este héroe haya sido igualmente un hombre de frontera que se movía en los márgenes permeables a la cultura del otro. Como plantea María Soledad Carrasco Urgoiti, la tregua era la condición más frecuente de la frontera hispánica medieval, donde se llevaban a cabo tratos, intercambios comerciales, visitas oficiales de dignatarios e incursiones clandestinas. En ellas, se intentaba a menudo pasar desapercibido usando el vestido, los gestos, y la lengua misma del estado vecino ( $E l$ gallardo, 572).

Surge ahora una consideración importante en relación con las resonancias que Cervantes logra suscitar a través de los nombres de sus personajes. La familia que encarnaba la cultura de la frontera durante varios siglos en la España medieval no era la de los Mendoza, ni la de los Fajardo, ni la de los Narváez. Era la de los Saavedra (Carrasco Urgoiti, «El gallardo», 575). Originalmente de Galicia, los Saavedra se establecieron en Sevilla alrededor de 1351 y en el siglo XV se habían convertido en uno de los linajes más influyentes de la ciudad, conocidos tanto por su defensa de la frontera con el reino de Granada como por sus correrías a través de estos territorios. Marcados por una intensa atracción hacia la frontera, los Saavedra hicieron su fortuna viviendo literalmente en el filo de estos linderos. Ser un Saavedra, como lo intuyó quizá Cervantes, era ser parte de un destino simultáneamente trágico y glorioso, un destino muchas veces sellado por la muerte. De hecho, Juan de Sayavedra, el héroe del romance medieval, era un miembro de los famosos Saavedra (o Sayavedra) de Sevilla. Como vimos antes, Sayavedra fue derrotado y capturado por los moros de Granada en una expedición de 1448, en la que casi todos sus hombres fueron masacrados. Llevado a Granada como cautivo, se le fijó como rescate la enorme suma de 12.000 doblas (Sánchez Saus, 163-82). Anotemos de pasada que las similitudes con la captura y el cautiverio de Cervantes son asombrosas.

\footnotetext{
${ }^{7}$ Por lo demás, el gobierno español tenía una deuda de 600.000 ducados con las guarniciones africanas en concepto de salarios atrasados, entre los que no se cuentan los salarios adeudados a los defensores de Orán (RODRÍGUEZ-SALGADO, Un imperio en transición, 411 y ss.).
} 
Los romances aparecidos en la frontera con Granada durante el siglo xv retomaron algunos de los incidentes históricos más relevantes, interpretando o comentando la vida pública contemporánea. De hecho, las refriegas fronterizas y la constante posibilidad de cautiverio a manos del enemigo le otorgaba una calidad aventurera a la existencia de soldados y líderes en los territorios de la frontera. Como sugiere Carrasco Urgoiti, este ambiente se intensifica en los romances fronterizos, basados en los antiguos romances tradicionales e influidos por un nuevo sentido de lo dramático que se interesaba por el destino individual, sujeto a súbitos cambios de fortuna (The Moorish Novel, 43-46). Es así como la captura de Juan de Sayavedra en la frontera con Granada dio pie a la creación de varios romances cuyo tenor afectivo subraya el impacto del incidente en la comunidad afectada por estos hechos ${ }^{8}$. Como ocurriría posteriormente en la Berbería del siglo XVI, el Saavedra del Romancero es tentado a apostatar y a pasarse al lado enemigo. En el «Romance de Sayavedra», el rey de Granada intenta convencer al cautivo con ofertas tentadoras: «Calles, calles, Sayavedra, / cese tu melancolía; / tórnate moro si quieres / y verás qué te daría:/ darte he villas y castillos / y joyas de gran valía» (vv. 26-28). Dentro de la tradición difundida por estos romances, el heroísmo de Sayavedra consiste en mantener su fe cristiana a pesar de estas promesas. El Romancero lo consagrará a la fama, haciéndolo morir en una emboscada.

\section{UN SEGUNDO NOMBRE}

A partir de 1586, aproximadamente seis años después de su regreso de Argel, Cervantes comienza a añadir el apellido Saavedra a su nombre, en documentos relacionados con su matrimonio con Catalina Palacios Salazar, así como en cartas enviadas dentro de sus funciones de comisario de la armada. Todo indica que Saavedra fue un nombre libremente escogido por Cervantes después de su liberación, y que esta elección apunta a una compleja red de significantes, en particular a problemas de identidad derivados del trauma del cautiverio. Así, el 9 de agosto de 1586, en Esquivias, Miguel de Cervantes Saavedra firma un documento reconociendo haber recibido la dote asignada a su esposa, Catalina de Palacios Salazar, en el que promete administrar adecuadamente estos bienes. En una segunda escritura firmada el mismo día, su suegra Catalina de Palacios nombra a Miguel de Cervantes Saavedra «administrador absoluto de toda su hacienda» (Sliwa, 138-43; Pérez Pastor, II: 98 y ss). Ocho meses después, en Toledo, el 28

\footnotetext{
${ }^{8}$ Aunque el hecho histórico de los romances de «Río Verde» se remonta a 1448 , estos romances fueron compuestos años más tarde, después de la muerte de Don Alonso de Aguilar a manos de los moriscos insurgentes en Granada, en 1601; véase Luis SECO DE LUCENA, Investigaciones sobre el romancero: Estudio de tres romances fronterizos.
} 
de abril de 1587, Miguel de Cervantes Saavedra le concede un poder general a su mujer Catalina Palacios Salazar con plena autoridad para hacer negocios en su nombre y para representarlo legalmente (Sliwa, 143-46) ${ }^{9}$. Al no haber logrado una posición en Castilla, Cervantes se aprestaba a viajar a Andalucía, donde trabajaría durante diez años aproximadamente como nuevo comisario general de abastos para las galeras de Felipe II. En casi todas las cartas y documentos firmados en Sevilla y en otras villas andaluzas después de 1587, su nombre aparece como Miguel de Cervantes Saavedra.

La adición de un segundo nombre - un apellido que no corresponde a la familia inmediata - resulta significativa en un hombre que estaba a punto de cumplir los cuarenta años y que acaba de casarse con una mujer casi veinte años menor -el matrimonio de Cervantes se celebra el 12 de diciembre de 1584. La importancia de esta acción debe ser señalada, aunque la adopción de un apellido distinto al del propio padre no constituye un hecho demasiado estrambótico en la España del siglo XVI. Los criminales cambiaban a menudo de nombre y de apellido, de la misma manera que los conversos procesados por la Inquisición — cuyos nombres se fijaban a los sambenitos colgados de los muros de las iglesias - se veían obligados a adoptar nuevos apelativos. La costumbre general que permitía a un individuo asumir un apellido diferente al de su padre es puesta de relieve por numerosas novelas y comedias del Siglo de Oro. En la misma línea que Cervantes, el escritor y dramaturgo Vélez de Guevara (1579-1644), cambió su nombre de bautizo, Luis Vélez de Santander, por el de Luis Vélez de Guevara, nombre por el cual es hoy conocido ${ }^{10}$. Vale añadir que el cambio de nombre en Vélez de Guevara obedece también de a una experiencia traumática de su juventud.

Por consiguiente, es un error sugerir, como han hecho varios estudiosos, que Cervantes debía haber usado el apellido de su madre, Cortinas, después de su patronímico ${ }^{11}$. La transmisión de patronímicos en la nobleza o baja nobleza castellana seguiría cursos complicados y a menudo imprevisibles hasta incluso más allá del siglo XVIII. En general, el apellido paterno se reservaba para el primogénito y los demás hijos mayores, mientras que el resto de la prole recibía otros apellidos del linaje, como los de

\footnotetext{
${ }^{9}$ Sobre Saavedra, véase ZMANTAR, «Miguel de Cervantes y sus fantasmas de Argel», así como su agudo análisis de estos temas en «Saavedra et les captifs du Trato de Argel de Miguel de Cervantes Saavedra».

${ }^{10}$ Cervantes alude con afecto a Vélez de Guevara, a quien llama «quitapesares»: «Topé a Luis Vélez, lustre y alegría / y discreción del trato cortesano, / y abracéle, en la calle, a medio día», Viaje del Parnaso, v. 394-96, en Cenvantes, Poesías completas, I: 175 .

11 Véanse a este respecto Canavaggio, 175; Combet, 553; y ZMANTAR, «Miguel de Cervantes y sus fantasmas de Argel», 186, entre otros.
} 
la madre y parientes cercanos. Magdalena, la propia hermana de Cervantes, asumió como adulta los apellidos Pimentel de Sotomayor en vez del patronímico Cervantes que le fue otorgado en el bautizo ${ }^{12}$. A su vez, la madre de Cervantes, Leonor de Cortinas, adoptó el apellido de su propia madre, quien, por su parte, tomó el de su padre. Para ilustrar estas complejidades, consideremos el caso del noble Nicolás de Ovando, amante de Andrea de Cervantes, hermana de Miguel. El primogénito Nicolás recibió el ilustre patronímico de su madre, María de Ovando, en vez del de su padre Luis Carrillo. El apellido de la madre era más prestigioso ${ }^{13}$. El resto de la prole recibió diferentes apellidos: algunos se llamaron Carrillo, otros Ovando, y el tercer hijo se llamó Bernal Francés de Zúñiga, en honor del abuelo paterno, un famoso capitán de los Reyes Católicos (Astrana Marín, II: 44-45).

\section{SAAVEDRA: GRITO DE GUERRA}

Estas complejidades me llevan a esbozar algunos rasgos sobre la constitución de los nombres y patronímicos en la España moderna, discusión con la que pretendo iluminar el problema del segundo apellido adoptado por Cervantes. A fines del siglo IX en España y otros países europeos, el nombre propio ya no era suficiente para distinguir a unos individuos de otros. Los patronímicos aparecieron durante este período, bajo la forma de un adjetivo terminado en ius, o de un genitivo del nombre del padre, costumbre posiblemente derivada de la tradición judía o musulmana: Fernández, hijo de Fernando, Sánchez, hijo de Sancho, Rodríguez, hijo de Rodrigo, etc. En el siglo XIII estas denominaciones eran cada vez más comunes, por lo que se comenzó a añadir al patronímico un apodo o sobrenombre, como un nombre adicional que evocaba una calidad moral o física, un defecto, un origen geográfico, o un oficio. En las familias aristocráticas, este apodo era generalmente reemplazado por el apellido que se originaba en el nombre del solar o casa ancestral que pertenecía al jefe de la familia (de los Ríos, 44-49).

La pequeña nobleza en la España medieval y moderna ostentaba su nombre de bautizo, seguido por el patronímico y por el apellido -el nombre del solar o casa ancestral- una denominación similar a la tria nomina nobiliarum de los romanos. Estos tres apelativos son claramente distin-

${ }^{12}$ Hay, entonces, en la familia de Cervantes, otro cambio de apellido voluntario. Curiosamente, Sotomayor era un apellido de la rama de los Cervantes Saavedra de Córdoba: le pertenecía a Alonso Cervantes de Sotomayor, un hermano de Gonzalo Cervantes Saavedra.

${ }^{13}$ Ovando era descendiente del famoso gobernador de Indias en la Española, Nicolás de Ovando (1502-1509), quien introdujo el régimen de encomienda de indios. 
guibles en el aristocrático nombre de Pedro Téllez de Girón, duque de Osuna: Pedro es su nombre individual, Téllez su patronímico, y Girón su apellido o sobrenombre, un verdadero apodo que funcionaba como el cognomen romano, es decir, como un sobrenombre individual. El término apellido que todavía designa a cada nombre de familia en España y en algunas partes de América Latina tiene, por tanto, un origen aristocrático y, como veremos, guerrero. En efecto, para Covarrubias, apellido viene del latín appello - hablar, apostrofar, invocar. El apellido era el grito de guerra o de mutuo reconocimiento de los cristianos durante el periodo de la Reconquista. Este grito servía para convocar a los guerreros, para darse valor mutuamente durante el combate, para reconocer a los compañeros de armas, para pedir ayuda y para cantar victoria. El apellido podía ser el nombre de un santo (;Santiago!) o el de un señor. A la vez, cada señor o amo se distinguía gracias al apellido que aludía a su solar ancestral y linaje, apellido que tanto él mismo como su clan invocaban a menudo. Estas conexiones entre el solar ancestral y el apellido son destacadas por Cervantes en su novela El Persiles, que describe el regreso del exiliado Antonio a su patria chica, cerca de Toledo: «Por ventura - pregunta el peregrino- ieste lugar no se llama el Quintanar de la Orden [de Santiago], y en él no vive un apellido de unos hidalgos que se llaman Villaseñores?» (Persiles, III, 9, 334) ${ }^{14}$. Asimismo, las estructuras de parentesco construidas en torno al apellido son evocadas por Mauricio, otro personaje cervantino, en el mismo Persiles, al referirse a su propio nombre: «Tuvo principio mi linaje, tan antiguo, bien como aquel que es de los Mauricios, que en decir este apellido le encarezco todo lo que puedo» (Persiles, I, 12, 111).

Cervantes también alude al verbo apellidar en el sentido de dar un grito de guerra, específicamente en la dramática escena de su novela El amante liberal, que describe el asalto de una galera turca por varios cautivos cristianos. Éstos se alzan en armas contra sus opresores y les cortan el cogote: «Saltaron en crujía, apellidando 'Libertad, libertad', y ayudados de las buenas boyas, cristianos griegos, con facilidad y sin recibir herida, los degollaron a todos» (El amante liberal, I: 181). Resulta muy significativo que en este escenario de cautiverio, el grito «iLibertad!» se convierte en el grito de guerra o apellido de los cautivos. La última acepción del termino es la que subraya Covarrubias en su Tesoro: «Apellidar, aclamar tomando la voz del rey, como: 'Aquí el rey, o Viva el rey'; y entre las parcialidades, declarándose a voces por una de ellas [...]. Y así los del apellido se juntan y llegan a su parcialidad. Y de aquí los nombres de las casas principales se llamaban apellidos, porque los demás se allegaban a

${ }^{14}$ Por las relaciones topográficas de Felipe II, se sabe, efectivamente, que una de las familias de hidalgos con ejecutoria en Quintanar de la Orden de Santiago eran los Villaseñores (Astrana Marín, VII: 438). 
ellos, y unos eran Oñez y otros Gamboa». Como lo revela esta definición, el apellido refería a las huestes convocadas por el grito de un mismo sobrenombre.

Más allá de un linaje aristocrático que alude a un lugar geográfico, el apellido a menudo rememoraba una hazaña heroica o reconocida. En otras palabras, el apellido también funcionaba como un sobrenombre o apodo literal. Éste es el caso del sobrenombre Machuca, otorgado al legendario Diego Pérez de Vargas por haber «machacado» a varios moros con un pesado tronco que arrancó de una encina, historia relatada por Don Quijote en el episodio de los molinos de viento (DQ I, 8). Desde entonces, como Don Quijote le explica a Sancho, Vargas y sus descendientes llevaron el nombre Vargas y Machuca $^{15}$. Una leyenda similar surgió en torno al apellido «de la Vega» ostentado por el poeta Garcilaso de la Vega y sus ancestros. Este apellido posiblemente se originó en una proeza realizada por un tal Gonzalo Ruiz de la Vega, quien se hizo famoso por haber matado a un moro que desafió a los cristianos al colgar de la cola de su caballo una cinta con la inscripción «Ave María.» La historia legendaria se reincorporó al ciclo de romances emanados de la conquista de Granada por los Reyes Católicos y recogidos por Ginés Pérez de Hita en sus Guerras Civiles de Granada. El Romancero revivió tanto el mítico triunfo sobre el moro desafiante como la historia del apellido que quizá proceda de esta hazaña: «Garcilaso de la Vega / desde allí se ha intitulado, / porque en la Vega hiziera / campo con aquel pagano» (Guerras civiles, ed. BlanchardDemouge, 283).

Para Cervantes, sin embargo, el apellido Saavedra no remite a un solar ancestral en una gran propiedad o extensión de terreno, sino más bien a la experiencia catastrófica del cautiverio argelino, experiencia que también incluyó proezas heroicas, como las realizadas por el fabuloso Saavedra del Romancero. Por consiguiente, a través de sus vínculos con un nombre legendario que evoca la valentía y audacia de los soldados fronterizos, el apellido Saavedra proclama la pertenencia de Cervantes al clan de los Saavedra, a la vez que bosqueja un linaje simbólico que asocia al ex-cautivo con el héroe de las guerras fronterizas con Granada. El celebrado Saavedra del Romancero fue un soldado aprehendido en franca lid, como Cervantes; más significativo aún, fue un cautivo que resistió las amenazas y las tentaciones del Islam, incluso frente a la muerte. Al adoptar el apellido Saavedra, Cervantes esbozaba un gesto de reconocimiento a un destino compartido. Saavedra, entonces, encarna una experiencia limítrofe:

\footnotetext{
${ }^{15}$ Diego Pérez de Vargas fue un personaje histórico que vivió en la época de Fernando III el Santo (1199-1252). La anécdota aparece en Diego RoDRíGUEZ DE ALMELA, Valerio de las historias escolásticas y de España, y en un romance de Lorenzo de Sepúlveda; véase Cervantes, Don Quijote de la Mancha, ed. Luis Andrés Murillo, I: 131, n. 12.
} 
tanto la vivencia del cautivo que sobrevivió al encuentro con la muerte, como la experiencia de vivir a caballo entre las fronteras geográficas y culturales que separaban a cristianos y musulmanes. En el siglo XVI, estas fronteras eran cruzadas por incontables individuos de las islas y costas mediterráneas, renegados que encontraban en tierras musulmanas nuevos horizontes y una vida más lucrativa como corsarios, artesanos, traductores o secretarios de los gobernantes de Berbería.

$\mathrm{Al}$ adoptar el apellido Saavedra, Cervantes estaría asumiendo la secuencia de tres nombres reservada para la pequeña nobleza castellana: Miguel de Cervantes Saavedra. En esta nueva apelación, Miguel es su nombre de bautizo, Cervantes su patronímico y Saavedra su apellido - su linaje. Por estas razones, propongo que Saavedra es un apellido en el sentido medieval explicado por Covarrubias: funciona como un clamor o grito de guerra que identifica a Cervantes con las huestes unidas por el sobrenombre Saavedra. Si este apellido aclama los hechos heroicos de Lepanto y de Argel, tanto a título individual como colectivo, también atestigua y lamenta simultáneamente la experiencia traumática del cautiverio argelino.

\section{MUERTE Y RENACIMIENTO}

Pero hay algo más. El apellido Saavedra parece reivindicar nuevas paternidades, como la que asume Cervantes en su Prólogo a las Novelas ejemplares: «Estas [novelas] son mías propias [...]; mi ingenio las engendró y las parió mi pluma, y van creciendo en los brazos de la estampa» (Novelas, I: 52). Desde una perspectiva vital y biológica, sin embargo, Saavedra es también el nombre que Cervantes le otorga a Isabel, la hija natural que tiene con la actriz Ana Franca. En los documentos recogidos por Pérez Pastor, la niña es llamada Isabel de Saavedra. Ella debe esperar hasta 1608 , año de su segundo matrimonio, para que los dos apellidos de su padre le sean finalmente conferidos, como lo confirma la carta de pago de su dote, donde aparece como «Isabel de Cervantes y Saavedra, [...] hija legítima de Miguel de Cervantes Saavedra» (Pérez Pastor, I: 131-37, 14755; las cursivas son mías). De paso, notemos que la composición y puesta en escena del El trato de Argel (c. 1581-1583) coincide aproximadamente con el nacimiento de Isabel de Saavedra - alrededor de 1584.

Para resumir: el lustro transcurrido entre 1581 y 1586 fue, pues, crucial para Cervantes. Marca su regreso a España después de su misión secreta a Orán; su reinserción en la sociedad española después de una ausencia de doce años, cinco de los cuales transcurrieron en los baños de Argel; la composición y puesta en escena de El trato de Argel y La Numancia, además de otras comedias aplaudidas por el público madrileño; y la publicación de su primera novela La Galatea (1585). Tres eventos cruciales cru- 
zan la intensa actividad literaria de este período: el nacimiento de su hija natural Isabel, que sin duda mantuvo en secreto; su matrimonio con Catalina de Salazar, en 1584; y la muerte de su padre, Rodrigo de Cervantes, en 1585.

La muerte del padre, como afirmó Freud, es «el acontecimiento más importante, la pérdida más desgarradora en la vida de un hombre» (Prólogo a La interpretación de los sueños, IV: xxvi). La muerte del padre sumergió a Freud en un intenso período de duelo que lo llevó a realizar un auto-análisis y a escribir un libro sobre los sueños (Anzieu, El autoanálisis de Freud). En un artículo esclarecedor sobre la muerte y la crisis del mediodía, Elliot Jaques ha demostrado que, alrededor de los cuarenta años, se produce una crisis enorme causada por la sensación de que no hay suficiente tiempo de vida, crisis acentuada por la muerte de los padres, que usualmente ocurre en esta época (502-14). En ciertos individuos especialmente dotados, esta crisis resulta en una liberación de posibilidades que permite que aquel o aquella que era meramente creativo o creativa se convierta finalmente en un creador o creadora, y que la persona que ya era un genio cambie de inspiración e, incluso, de géneros de producción. Para crear, como aduce Didier Anzieu, es siempre necesario matar a alguien, de una manera imaginaria o simbólica. El proceso se facilita si alguien acaba de morir, porque podemos matar a esa persona sin culpa.

No sabemos si el proceso de duelo por la muerte del padre puso en marcha en Cervantes un trabajo de intensa elaboración psíquica que tuvo efectos liberadores para su creación. Su adopción del apellido Saavedra, sin embargo, se da en esta agitada etapa de su vida. Podemos asumir, en consecuencia, que más allá de la compleja red simbólica que el patronímico Saavedra invoca, su adopción por parte de Cervantes se encuentra vinculada tanto a la muerte del padre, como al nacimiento de nuevas ilusiones. Recapitulemos: la adición del apellido Saavedra surge durante un fértil periodo de producción literaria - como indican las veinte o treinta comedias puestas en escena por Cervantes en las fases iniciales de su carrera y la publicación de La Galatea (1585). Más específicamente, Saavedra surge en el contexto de dos empresas inaugurales: es el nombre del héroe en la primera obra dramática de Cervantes, y también el nombre otorgado a su primera y única hija, Isabel. Los primeros documentos que llevan los dos apellidos - Cervantes y Saavedra - aparecen en 1586, aproximadamente un año después de la muerte del padre y en el contexto de su matrimonio con Catalina de Salazar. El nuevo apellido, asociado con la creación, parece erigirse como una defensa contra la muerte, una afirmación de la vida que apunta a la inmortalidad.

Varios años más tarde, en La historia del cautivo, interpolada en $\mathrm{El}$ Quijote, Primera parte (1605), Cervantes asume el nombre de Saavedra, ya no como una identidad camuflada que reivindica el heroísmo de los cauti- 
vos cristianos, sino como una segunda identidad que habla de su experiencia traumática en Argel. Recordemos que Saavedra, en este relato, es el nombre del esclavo cristiano cuya valerosa actuación frente al gobernador de Argel Hasán Pachá suscita la admiración del protagonista Ruy Pérez de Viedma, un doble de Cervantes. Considerada como una mezcla de autobiografía y de ficción, La historia del cautivo está doblemente signada, inicialmente por una fecha que nos permite situar cronológicamente la narración del capitán cautivo: «Este hará veinte y dos años que salí de la casa de mi padre», anuncia el cautivo Pérez de Viedma al comenzar su narración (DQ I, 39) ${ }^{16}$. Puesto que el Cautivo salió de España con el Duque de Alba, quien asumió el gobierno de Flandes en 1567 - y puesto que fue testigo de la ejecución de los condes de Egmont y de Horn, ocurridas el 5 de junio de 1568 - podemos concluir que su narración en la venta de Juan Palomeque tiene lugar entre 1589 y 1590 —veintidós años después de salir de la casa de su padre. Dada la costumbre de Cervantes de fechar sus obras dentro de su misma ficción, algunos críticos han supuesto que La historia del cautivo fue redactada en 1589, como un cuento autónomo que luego fue incluido en El Quijote (Allen, «Autobiografía, 151; Murillo, The Golden Dial, 73-98).

Fechar es firmar, como nos recuerda Derrida, y fechar desde alguna parte es también identificar el lugar de la firma (Otobiographies, 11). Varias fechas y firmas cruzan La historia del cautivo, marcando puntos críticos en la narración autobiográfica del Cautivo. Aunque la primea fecha identifica a La Mancha como el lugar originario de la signatura, el relato del Cautivo se desliza en seguida hacia el Mediterráneo, para retornar, una vez más, a los baños de Argel. Y es en la recreación de la propia esclavitud argelina donde reaparece una firma significativa, esta vez como la contraseña del propio nombre de Cervantes: «Un soldado español, llamado tal de Saavedra» (DQ I, 40). Encarnado en esta firma - Saavedra- el cuerpo de Cervantes surge como una aparición fantasmal en la puesta en escena de su propio cautiverio.

De ahí que el apellido Saavedra señale tanto el umbral entre la vida y la muerte como los avatares de la creación. Hemos visto que Saavedra también invoca la frontera entre el mundo cristiano y el mundo musulmán, entre el universo limítrofe de los renegados y el espacio ambiguo de los que retornaban a España «manchados» por el largo cautiverio en Berbería. La historia del cautivo confirma esta posición limítrofe del personaje llamado «un tal de Saavedra». Su intrusión en el relato del capitán cautivo Ruy Pérez de Viedma corta en dos la narración, e introduce la maravillosa

${ }^{16}$ La Historia del cautivo ha suscitado un enorme corpus de literatura crítica; véanse, entre otros, Allen; GARCÉs, «Cervantes's Veiled Woman» y Cervantes in Algiers, 182229; GERLI, «Writing Myth and History»; Riley, y Sánchez. 
historia de la mora Zoraida y de su huida conjunta de Berbería. La imagen de Zoraida surge inmediatamente después de la aparición de Saavedra en la ficción de Cervantes, como si la misma mano que marcara un hiato en el texto al firmarlo con el nombre de Cervantes se convirtiera en la enigmática mano femenina que aparece y desaparece detrás de las celosías que miran al baño del bey de Argel (Garcés, «Cervantes's Veiled Woman», 821-830). Como han señalado algunos críticos, desde este momento, la autobiografía se convierte en leyenda, en ficción.

\section{SAAVEDRA: FRONTERA ENTRE LA BIOGRAFÍA Y LA FICCIÓN}

Más allá del mundo fronterizo de Argel, por consiguiente, Saavedra representa el núcleo de la creación en la obra cervantina. En Cervantes in Algiers: A Captive's Tale, he mostrado cómo la reconstrucción de las memorias traumáticas del cautiverio opera en Cervantes como fuente de creación. Desde esta perspectiva, resulta especialmente sugestiva la tesis de Juan Goytisolo, quien sostiene que el cautiverio de Cervantes es «ese vacío-hueco, vórtice, remolino-en el núcleo central de la gran invención literaria» (Crónicas sarracinas, 60). Ciertamente, la puesta en escena de la experiencia traumática del cautiverio en la producción literaria cervantina produce una explosión de fantasía que lleva a otra realidad, una realidad que alude oblicuamente al evento traumático en sí, mientras que opera simultáneamente como testimonio artístico del trauma.

Es significativo que el testimonio artístico del cautiverio se da desde la frontera entre dos mundos. Por lo general, la rememoración del cautiverio en la obra de Cervantes surge en el enfrentamiento marítimo entre cristianos y musulmanes, usualmente mediante la recreación del momento mismo de la captura. Si esta angustiosa coyuntura, magistralmente evocada por la pluma de Cervantes, marca un sinnúmero de encuentros entre cristianos y musulmanes, también señala la tenue línea divisoria entre ambos bandos en la producción literaria cervantina. No es fortuito entonces que, tanto en los romances donde se canta al legendario Saavedra de las guerras con Granada, como en El gallardo español de Cervantes, Saavedra designe a un hombre de frontera. Como hemos visto, el protagonista de la comedia cervantina, don Fernando de Saavedra, oscila entre varios nombres e identidades, hasta el punto de que, hablando con un personaje que lo cree moro por su vestido, alude a Saavedra como su «otro yo» (Gallar$d o$, v. 2581). Paradójicamente, el Saavedra de El trato de Argel revela la misma oscilación entre las fronteras cristianas y musulmanas. También aquí Saavedra tiene dos caras: es el soldado cristiano que mantiene su fe hasta el final, pero, a la vez, es el doble invertido del cautivo Aurelio, quien casi sucumbe ante los avances del Islam. 
La escisión del héroe en estas obras no es accidental. El trauma extremo a menudo crea un segundo yo. El trauma altera radicalmente el sentido propio del yo, incluso hasta crear un otro yo, que aparece como un doble de la persona traumatizada. La duplicación del yo en el trauma severo es un proceso psicológico activo, una forma de adaptación a una extrema vicisitud, como explica Robert Jay Lifton. En The Broken Connection, Lifton plantea que el sobreviviente sufre una forma reversible de muerte para evitar una muerte permanente, física o psicológica (70). La anestesia o insensibilización psíquica que se da en respuesta a la forma más aguda del trauma se caracteriza por una severa escisión del yo, de manera que varios yos separados o contradictorios parecen coexistir en el sujeto. Ciertamente, esta desintegración disociadora, en el sentido de la escisión de componentes cruciales del yo, es parcial y, en gran medida, temporal -un proceso que intenta evitar una desintegración psíquica más total y perdurable. Ahora bien: como ilustra Sándor Ferenczi, la escisión del yo en el trauma mide, por así decirlo, la extensión o importancia del daño, a la vez que indica la parte del yo que el sujeto puede tolerar, permitiendo el acceso a la percepción de solo lo que puede ser soportado («Refléxions» 144-46).

Como sugieren estas líneas, la ficción cervantina se entreteje con la propia vida y con los propios procesos psicológicos del sujeto Cervantes, en un complejo juego de espejos que resulta, a menudo, reiterativo. Así, el 21 de mayo de 1590, Cervantes le dirige un memorial al Presidente del Consejo de Indias, solicitando un puesto en América. La petición parece haber sido redactada en el mismo período en que Cervantes compone $L a$ historia del cautivo, porque tiene asombrosas coincidencias con este relato. En el memorial, Miguel de Cervantes Saavedra afirma que ha servido a «Vuestra Majestad muchos años en las jornadas de mar y tierra que se han ofrescido de veinte y dos años a esta parte» (Astrana Marín, IV: 455456; Sliwa, 225-226; las cursivas son mías). Su declaración reitera la afirmación del capitán cautivo: «hace veinte y dos años que salí de la casa de mi padre» (DQ I, 39; las cursivas son mías). El documento oficial pasa a enumerar los servicios de Cervantes a la corona, incluyendo su cautiverio en Argel, bajo el nombre de Miguel de Cervantes Saavedra. Los paralelos del memorial con La historia del cautivo son extraordinarios. El primero parece ser un bosquejo o pre-texto del relato que desarrolla el Cautivo, también firmado con el nombre de Saavedra.

Cabe preguntarnos cuán consciente fue Cervantes de estos juegos onomásticos que cruzan su vida y su obra. Es indudable que un escritor tan preocupado por la onomástica —un autor que demuestra claramente su interés por la trasmisión de patronímicos y apellidos en la España medieval y moderna - tuvo plena consciencia del significado de los nombres otorgados a sus personajes, más aún, cuando algunos de estos nombres se 
repiten insistentemente en su obra. Con referencia a la onomástica y la poética renacentistas, François Rigolot ha propuesto que ninguna época ha meditado sobre el poder de los nombres con tanta devoción como el Renacimiento ${ }^{17}$. En España, Fray Luis de León afirma en De los nombres de Cristo (1583) que cada uno es lo que su nombre significa: "Quede por cierto que todos los nombres que se ponen por orden de Dios traen consigo significación de un particular secreto que la cosa nombrada en sí tiene, y que esta significación se asemeja a ella» (De los nombres de Cristo, 21). Ciertamente, este gusto por la semantización del nombre propio llega a su cenit en la España áurea con escritores como Cervantes, Quevedo, Góngora y Gracián, cuyas obras revelan un juego excepcional de invención onomástica. Francisco Sánchez de las Brozas, El Brocense, captura el espíritu de la época con una frase lapidaria: «Todo es cuestión de nombres. No hay nombre acomodado» (Que nada se sabe, 35).

Que «no hay nombre acomodado» parece ser un hecho cierto en relación con Cervantes. Si el primer capítulo de El Quijote de 1605 esboza una poética basada en la onomástica (pensemos en Quijano $\rightarrow$ Quijada $\rightarrow$ Quijote $\rightarrow$; Rocín-ante), también revela el cuidado minucioso con que el escritor construye el universo heroico de su novela, un mundo que cobra vida a través del despliegue continuo de una asombrosa selección de nombres. Esta extraordinaria capacidad de invención onomástica hace decir a Pedro Salinas, hablando de la aventura de las ovejas en El Quijote, que «el polvo de La Mancha se va a poblar de nombres» (213). Como anota Salinas, cada nombre en Cervantes es una pequeña aventura, donde cada sílaba se juega contra otra sílaba, y donde la fonética se enfrenta al significado. Este antagonismo semántico/silábico expone la manera en que detalles aparentemente nimios, como la composición de un nombre, apuntan misteriosamente a la concepción global de la novela (Salinas 218). El esmero con que Cervantes elige los nombres de los personajes que pueblan su universo literario y el sentido que adquiere cada nombre en su obra sugieren una clara voluntad en la elección del nombre Saavedra, por lo menos en la producción artística cervantina. El hecho de que esta producción esté tan íntimamente entrelazada con la vida y los procesos psíquicos del autor, como hemos visto, abre otras preguntas acerca de las operaciones inconscientes que subyacen en el proceso de adopción del apellido Saavedra en Cervantes. Este ensayo constituye una respuesta a algunas de estas preguntas.

Para concluir, regreso a Derrida con quien di inicio a estas páginas. Saavedra alude a esa frontera entre vida y creación, descrita por Derrida

${ }^{17}$ Rabelais hace que su mago pronostique mediante la onomancia [onomantocie], mientras que Nostradamus compone una Onomantia en una vena misteriosa que recuerda el lenguaje de sus Profecías (Rigolot, 14). 
en otro contexto. En la frontera entre el cuerpo y el corpus literario de Cervantes, el nombre Saavedra es simultáneamente una firma, una línea divisoria, una herida sangrante y una geografía. Saavedra encarna la experiencia limítrofe desde la cual la vida es recitada, las heridas de Lepanto pero, sobre todo, el cautiverio de Argel. Este nombre simboliza la vivencia anticipada de la muerte, revivida a diario durante el cautiverio y, simultáneamente, una respuesta a la misma, que se erige a partir de la creación. Como plantea Derrida en su hermoso artículo sobre la muerte de Roland Barthes, «la muerte se inscribe precisamente en el nombre» («The Deaths of Roland Barthes», 34). Más allá del patronímico Cervantes que evoca tanto a la persona muerta como a su obra, la muerte se inscribe en el nuevo apellido escogido por el autor: Saavedra.

Saavedra no solo traza la huella del trauma en Cervantes: también representa la marca de la otredad en la nueva identidad que se construye paulatinamente a través del tejido de vida y obra. Saavedra, por tanto, simboliza la frontera o límite fluctuante entre la biografía y la creación literaria, una frontera donde lo biológico y lo biográfico se entretejen con la ficción. Saavedra apunta así a la frontera entre el cuerpo y la obra, al dinámico confín que habla del cruce entre vida, muerte y creación. Con relación a la firma de los dos apellidos - Cervantes Saavedra- que comienza a darse partir de 1586, quiero proponer que, a lo largo de estos años, el escritor se ha venido recuperando de las secuelas del trauma, juntando el nombre Saavedra a su propio apellido Cervantes, y soldando así los yos escindidos que aparecen como entidades separadas en su ficción. Es bajo el nombre de Miguel de Cervantes Saavedra que el autor de $E l$ Quijote lega su creación a la historia, con la obra maestra que lo consagra ante la posteridad.

\section{BIBLIOGRAFÍA}

Allen, John J., «Autobiografía y ficción: el relato del Capitán Cautivo (Don Quijote I, 39-41)», Anales Cervantinos 15 (1976): 149-55.

ANZIEU, Didier, El autoanálisis de Freud: Descubrimiento del psicoanálisis. Trad. Ulises Guiñazú, México: Siglo XXI, 1980.

ASTRANA MARÍn, Luis, Vida ejemplar y heroica de Miguel de Cervantes Saavedra, 7 vols. Madrid: Instituto Editorial Reus, 1949-52.

Avalle-ArCE, Juan Bautista, «La captura de Cervantes», Boletín de la Real Academia Española 48 (1968): 237-80.

Bennington, Geoffrey y Jacques DeRRIDA, Jacques Derrida. Trad. Geoffrey Bennington, Chicago: University of Chicago Press, 1999.

Canavaggio, Jean, Cervantes: En busca del perfil perdido. Trad. Mauro Armiño, $2^{\mathrm{a}}$ edición, Madrid: Espasa-Calpe, 1992.

CAZENAVE, Jean, "Cervantès à Oran, 1581», Société de géographie et d'archéologie d'Oran 43 (1923): 215-42. 
—, «El gallardo español de Cervantes (1)». Langues Néo-Latines 126 (1953): 5-17.

—, «El gallardo español de Cervantes (2)», Langues Néo-Latines 127 (1953): 3-14.

CERVANTES, Miguel de, El amante liberal. Novelas ejemplares, Ed. Harry Sieber, 2 vols. Madrid: Cátedra, 1998, I: 135-188.

-, El gallardo español, Ed. Florencio Sevilla Arroyo y Antonio Rey Hazas, vol. 14 de Obra completa de Miguel de Cervantes, 18 vols. Madrid: Alianza, 1997.

-, El trato de Argel, Ed. Florencio Sevilla Arroyo y Antonio Rey Hazas, vol. 2 de Obra completa de Miguel de Cervantes, 18 vols. Madrid: Alianza, 1997.

-, Don Quijote de la Mancha, Ed. Luis Andrés Murillo, 2 vols. Madrid: Castalia, 1978.

-, La Galatea, Ed. Francisco Estrada y María Teresa López García-Berdoy, Madrid: Cátedra, 1996.

-, Novelas ejemplares, Ed. Harry Sieber, 2 vols., Madrid: Cátedra, 1988.

-, Los trabajos de Persiles y Sigismunda, Ed. Juan Bautista Avalle-Arce, Madrid: Castalia, 1970.

—, Viaje del Parnaso. Poesías completas, Ed. Vicente Gaos, Madrid: Castalia, 1970.

CARrasco, María Soledad, The Moorish Novel: «El Abencerraje» and "Pérez de Hita», Boston: Twayne, 1976.

CARRASCo URGOITI, María Soledad, «El gallardo español como héroe fronterizo», Actas del Tercer Congreso Internacional de Cervantistas, Gala Galdana, Menorca, 2025 de octubre de 1997. Palma: Universitat de Islas Baleares, 1998, 571-81

COMBET, Louis, Cervantès et les incertitudes du désir, Lyon: Presses Universitaires de Lyon, 1980.

COVARRUBias Horozco, Sebastián de, Tesoro de la lengua castellana o española, Ed. Felipe C.R. Maldonado, Madrid: Castalia, 1994.

DERRIDA, Jacques, «The Deaths of Roland Barthes», The Work of Mourning, Ed. PascaleAnne Brault and Michael Naas, Chicago: University of Chicago Press, 2001.

-, Otobiographies: L'enseignement de Nietzsche et la politique du nom propre, Paris: Galilée, 1984.

-, The Ear of the Other. Otobiography, Transference, Translation, Ed. Christie Mc Donald, Trad. Peggy Kamuf. Lincoln: University of Nebraska Press, 1988.

EISENBERG, Daniel, «¿Por qué volvió Cervantes de Argel?», Ingeniosa invención: Essays on Golden Age Literature Presented to Geoffrey Stagg on His Eighty-Fifth Birthday, Ed. Ellen Anderson and Amy Williamsen, Newark: Juan de la Cuesta, 1998, 241-53.

FERENCZI, Sándor, «Réflexions sur le traumatisme», Trad. Coq Héron et al., Oeuvres complètes de Sándor Ferenczi, 1927-1933. Psychanalyse 4, vol. 4, Paris: Payot, 1982.

FREUD, Sigmund. Prólogo a la 2. ${ }^{a}$ edición de La interpretación de los sueños. Sigmund Freud, Obras completas, vol. 4, Ed. James Strachey, Trad. José L. Etcheverry, 24 vols, Buenos Aires: Amorrortu, 1976.

Garcés, María Antonia, Cervantes in Algiers: A Captive's Tale, Nashville: Vanderbilt University Press, 2002.

-, «Cervantes's Veiled Woman». The New Norton Critical Edition of Cervantes, Don Quijote, Trad. Burton Raffel. Ed. Diana de Armas Wilson, New York: Norton, 1998, 821-30.

-, "Cuando llegué cautivo': Trauma and testimony in El trato de Argel». Cervantes for the 21st Century /Cervantes para el siglo XXI, Studies in Honor of Edward Dudley, Ed. Francisco LaRubia Prado, Newark: Juan de la Cuesta, 2001, 79-105.

-, «Zoraida's Veil: The 'Other' Scene of The Captive's Tale». Revista de Estudios Hispánicos 23 (1989): 65-98.

García ARENAL, Mercedes y Miguel Ángel DE BUNES, Los españoles en el norte de África siglos XV-XVIII, Madrid: MAPFRE, 1992.

GERLI, E. Michael, «Aristotle in Africa: History, Fiction, and Truth in El gallardo español», Cervantes 15 (1995): 43-57. 
-, «Writing Myth and History: Discourses of Race, Marginality, and Resistance in the Captive's Tale (Don Quijote I, 37-42)». Refiguring Authority: Reading, Writing, and Rewriting in Cervantes, Lexington: University Press of Kentucky, 1995, 40-60.

GoYtisolo, Juan, Crónicas sarracinas, Barcelona: Ibérica de Ediciones y Publicaciones, 1982.

HAEDo, Diego, Ed., Topografía e historia general de Argel, Ed. Ignacio Bauer y Landauer, 3 vols., Madrid: Sociedad de Bibliófilos Españoles, 1927-29.

JAQUES, Elliott, «Death and the Mid-Life Crisis», International Journal of Psycho-Analysis 46 (1965): 502-14.

LEÓn, Luis de, De los nombres de Cristo, Madrid: Espasa-Calpe, 1978.

Lifton, Robert Jay, The Broken Connection: On Death and the Continuity of Life, New York: Basic Books, 1987.

MENÉNDEZ PIDAL, Ramón, Estudios sobre el Romancero español (Obras completas, XI), Madrid: Espasa-Calpe, 1970.

Morón ARroyo, Ciriaco, Nuevas meditaciones del Quijote, Madrid: Gredos, 1976.

Oliver Asín, Jaime, «La hija de Agi Morato», Boletín de la Real Academia Española 27 (1947-48): 245-339.

PÉREZ DE HITA, Ginés, Guerras Civiles de Granada, Ed. Shasta Bryant, Newark: Juan de la Cuesta, 1982.

- Historia de los zegríes y abencerrajes (Primera parte de las Guerras civiles de Granada), Ed. Paula-Blanchard-Demouge, Madrid: Imprenta de E. Bailly-Baillière, 1913. Nueva edición crítica de Pedro Correa. Granada: Universidad de Granada, 1999.

PÉREZ PASTOR, Cristóbal, Documentos cervantinos hasta ahora inéditos, 2 vols., Madrid: Establecimiento Tipográfico de Fortanet, 1897-1902.

REDONDO, Augustin, «Moros y moriscos en la literatura española de los años 1550-1580», Judeoconversos y moriscos en la literatura del Siglo de Oro: Actas del "Grand Séminaire» de Neuchâtel, Neuchâtel, 26 a 27 de mayo de 1994, Ed. Irene AndresSuárez. Paris: Diffusion Les Belles Lettres, 1995, 51-83.

Rigolot, François, Poétique et onomastique: L'exemple de la Renaissance, Genève: Librairie Droz, 1977.

Ríos, Ángel de los, Ensayo histórico, etimológico y filológico sobre los apellidos castellanos desde el siglo X hasta nuestra Edad, Madrid: Imprenta de M. Tello, 1871.

RILEY, Edward C., «Episodio, novela, y aventura en Don Quijote». Anales Cervantinos 5 (1955-1956): 209-30.

RoDRÍGUEZ MARÍN, Francisco, «Los Cervantes cordobeses que no son parientes del autor del 'Quijote,' lo son en grado lejano», Estudios Cervantinos. Madrid: Atlas, 1947. 158-64.

SAlINAS, Pedro. «El polvo y los nombres». Cuadernos Hispanoamericanos 11 (1952): 211-25

SÁNCHEZ, Alberto. «Revisión del cautiverio cervantino en Argel». Cervantes 17 (1997): 7-24.

SÁNCHEZ, Francisco. Que nada se sabe. (Traducción de De multum nobili et prima universali scientia quod nihil scitur). Buenos Aires: Empecé Editores, 1944.

SÁNCHEZ SAUS, Rafael, «Los Saavedra y la frontera con el reino de Granada en el siglo $\mathrm{XV}$ », Estudios sobre Málaga y el Reino de Granada en el V Centenario de la Conquista, Málaga: Servicio de Publicaciones de la Universidad, Diputación Provincial de Málaga, 1987, 163-82.

SECO DE LUCENA, Luis, Discurso de apertura, Universidad de Granada: curso 1958-59. Investigaciones sobre el romancero: Estudio de tres romances fronterizos. Granada: Universidad de Granada, 1958.

SLIWA, K., Documentos de Miguel de Cervantes Saavedra, Pamplona: EUNSA, 1999. 
SolA, Emilio y José F. DE LA PEÑA, Cervantes y la Berbería: Cervantes, mundo turcoberberisco y servicios secretos en la época de Felipe II. México: Fondo de Cultura Económica, 1995.

Sosa, Antonio de, Diálogo de los mártires de Argel, Ed. Emilio Sola y José M. Parreño, Madrid: Hiperión, 1990.

-, Topografía e historia general de Argel, Ed. Diego de Haedo. Ignacio Bauer y Landauer, Ed. 3 vols., Madrid: Sociedad de Bibliófilos Españoles, 1927-29.

ZIMIC, Stanislav. «El gallardo español». El teatro de Cervantes, Madrid: Castalia, 1992, 87-117.

ZMANTAR, Françoise, «Miguel de Cervantes y sus fantasmas de Argel». Quimera 2, Diciembre 1980, 31-7.

-, «Saavedra et les captifs du Trato de Argel de Miguel de Cervantes Saavedra». L'Autobiographie dans le monde hispanique: Actes de Coloque Internacional de la Baumelès-Aix, 11-13 mai 1979. Aix-en-Provence: Université de Provence, 1980, 185-203.

VARGAS, Fray Bernardo de, Cronica Sacri et militare Ordinis B. Mariae de Mercede, redemptionis captivorvm [...], Palermo, 1622, 107-109. 


\title{
RESUMEN
}

\section{Los avatares de un nombre: Saavedra y Cervantes, por María Antonia Garcés}

Saavedra no era el apellido de Cervantes, ni tampoco un patronímico que llevaran sus antepasados directos. El escritor asumió este apellido algunos años después de su retorno de Argel, donde estuvo cautivo desde 1575 hasta 1580. Este apelativo adquiere una significación extraordinaria a la luz de la creación literaria cervantina, porque Saavedra es también el nombre otorgado por el autor a los protagonistas de sus dramas El trato de Argel y El gallardo español, así como a otro personaje en La historia del cautivo, interpolada en El Quijote de 1605 . Este ensayo examina la adopción del apellido Saavedra por parte de Miguel de Cervantes desde perspectivas interdisciplinarias, como la historia literaria, la teoría psicoanalítica y el estudio de las fronteras entre la autobiografía y la ficción en el autor alcalaíno. Saavedra representa un testimonio de la experiencia limítrofe del cautiverio y, simultáneamente, una respuesta a la misma, que se erige a partir de la creación.

Palabras clave: Saavedra, Cervantes Saavedra, autobiografía, cautiverio, ficción, fronteras, Literatura del Siglo de Oro, onomástica, transmisión de patronímicos en la España moderna.

\begin{abstract}
Saavedra was not Cervantes's last name, nor one that his direct ancestors bore. The writer assumed this surname after his return from Barbary, where he was a captive from 1575 to 1580 . This surname acquires an extraordinary significance in the light of the Cervantine literary production, because Saavedra is also the name granted by Cervantes to the protagonists of his dramas El trato de Argel and El gallardo español, and to a character in La historia del cautivo, interpolated in Don Quijote Part I. This essay examines the adoption of the patronymic Saavedra by Miguel de Cervantes from interdisciplinary perspectives, such as literary history, psychoanalytic theory, and a study of the frontiers between autobiography and fiction in the Spanish author. Saavedra represents a testimony of the limit experience of captivity and, simultaneously, a response to this experience emerging from artistic creation.
\end{abstract}

Key words: Saavedra, Cervantes Saavedra, autobiography, captivity, frontiers, Golden Age literature, onomastics, transmission of patronymics in early modern Spain. 